\title{
Effect of FFD-410 (HiOwna-Jr.), a Balanced Herbal Nutritional Supplement on Biochemical, Hematological, Immunological and Cognitive Parameters of Wistar Rats*
}

\author{
Suryakanth Dattatraya Anturlikar, Mohamed Rafiq", Gollapalle Laksminarayanashastry Viswanatha, \\ Mohammed Azeemuddin, Agadi Hiremath Thippeswamy, Uday Kumar Veeranna Kanni, \\ Pralhad Sadashiv Patki
}

Department of Pharmacology, R\&D Center, The Himalaya Drug Company, Bangalore, India.

Email: "dr.rafiq@himalayahealthcare.com

Received May 21 $1^{\text {st }}, 2012$; revised February $28^{\text {th }}, 2013$; accepted March $7^{\text {th }}, 2013$

Copyright (c) 2013 Suryakanth Dattatraya Anturlikar et al. This is an open access article distributed under the Creative Commons Attribution License, which permits unrestricted use, distribution, and reproduction in any medium, provided the original work is properly cited.

\begin{abstract}
Present study was aimed to evaluate the effect HiOwna-Jr. (FFD-410) on vital biochemical, hematological, immunological and cognitive functions in rats; also in vitro antioxidant studies were carried out to evaluate the antioxidant capacity of FFD-410. Animals of respective groups were treatment with FFD-410 for 90 days and blood samples were collected for the estimation of biochemical, hematological parameters and serum immunoglobulin levels; haemoagglutination assay was carried out using Sheep Red blood cells (SRBC's). In addition, effect of FFD-410 on cognition and memory was evaluated by modified elevated plus maze test. Apart from in vivo studies, in vitro studies such as DPPH radical scavenging assay, reducing power assay and ORAC assays were carried out to evaluate the free radical scavenging and antioxidant activity of FFD-410. Pretreatment with FFD-410 for 90 days did not bring about any change in serum biochemical and hematological parameters and relative organ weights etc., which could account for its wide safety margin at tested dose levels (2.5 and $5.0 \mathrm{~g} / \mathrm{kg}$, p.o.). However, FFD-410 showed potent immunostimulant activity by elevating the serum immunoglobulins and haemoagglutination titer values, also the pretreatment with FFD-410 showed dose dependent improvement in short-term cognition and memory in elevated plus maze test. Furthermore, in vitro antioxidant studies FFD-410 exhibited significant and dose dependent free radical scavenging and antioxidant activity as assessed by DPPH (IC 50 value of $1162.6 \mu \mathrm{g} / \mathrm{ml}$ ), reducing power and ORAC assays (Trolox equivalence/g of 76.1). These findings suggest that, FFD-410 possess very good antioxidant, cognition improving and potent immunostimulant properties. Also, there was no significant change in the serum biochemical and hematological parameters and relative organ weights were observed after 90 days treatment with FFD-410, which could account for its wide safety of margin at tested dose levels (2.5 and $5.0 \mathrm{~g} / \mathrm{kg}$. p.o.).
\end{abstract}

Keywords: HiOwna-Jr.; Herbal Nutritional Supplement; Antioxidants; ORAC Assay; Hematology; Immunomodulator; Cognition Improvement

\section{Introduction}

Dietary/Nutritional factors are well known to play a pivotal role in enhancement of health status and physical strength in human [1]. The portion of any nutrient that is immediately available for metabolic processes of the organism after absorption is called as available portion of the nutrition; nutritional value of a food is decided based on its chemical composition [2].

\footnotetext{
"Conflicts of interest: The authors declare no conflicts of interest.

\#Corresponding author.
}

In US, majority of the adults are regularly using the products containing essential nutritional supplements in order to maintain wellness or treat an illness. In this context, natural products are very commonly used in the folk medicine to treat various nutrition related diseases/disorders, but the information supporting the efficacy of natural products was anecdotal [3].

However, high quality and hypothesis-driven studies in animals and humans as well as in vitro systems have greatly contributed to our knowledge of the safety and efficacy of these products and also have helped in under- 
standing the underlying mechanisms [3]. As a consequence, an ever increasing number of phytochemicals are being recognized not only for their abilities to prevent disease states and support wellness (chemoprotective properties), but also to effectively treat various diseases [4].

In literature, several investigators have reported that, ingestion of some plant extracts and food supplements from fruits and vegetable origin are highly beneficial in combating the nutritional deficient states [5]. In addition to satisfying the daily nutritional demands, most of the daily consumed vegetables and fruits have been scientifically proved to possess medicinal properties such as immunomodulatory activity [6,7], anti-oxidant activity [8, 9], anticancer activity [10], anti-diabetic activity [11], antiulcer activity [12], anti-diarrheal activity [13], memory enhancing [14] and wound healing [15] activity. In this context, formulations/preparations containing herbal supplements are thought to be beneficial in fulfilling the daily nutritional demands and maintaining the normal gustatory functions.

FFD-410 (HiOwna-Jr.) is a herbal-based, nutritionally balanced pediatric health drink manufactured by the Himalaya Drug Company, Bangalore, India, as a supplement for childrens. Each five grams of FFD-410 contains extracts of plants Eleusine coracana-20 mg; Centella asiatica - $15 \mathrm{mg}$ and powders of Colostrum -7 mg; Emblica officinalis $-50 \mathrm{mg}$ and Piper nigrum-6 mg. FFD410 is nutritionally well balanced and rich in all the essential nutrients such as carbohydrates, proteins, fats, vitamins and minerals. Each $25 \mathrm{~g}$ of FFD-410 powders serves approximately $87.0 \mathrm{kcals}$ of energy to meet the daily metabolic needs. With this background present study was undertaken to evaluate the effect of FFD-410 on biochemical, haematology, immunological and cognitive functions in rats; also in vitro antioxidant studies were carried out to evaluate its antioxidant/free radical capacity.

\section{Materials and Methods}

\subsection{Drugs and Chemicals}

Trolox (Sigma-aldrich, Bangalore), Fluoroscein (Sigmaaldrich, Bangalore), (1, 1-diphenyl-2-picrylhydrazyl (Sigma-aldrich, Bangalore), biochemical kits (Erba diagnostic) and all other chemicals and reagents used for the study were of Analytical grade and purchased from Himedia Laboratories Pvt Ltd.

\subsection{Experimental Animals}

Inbred wistar rats (Body weight of 120 - 140 grams, 6 weeks old) were used for the study. The animals were maintained in polypropylene cages at a temperature of $25^{\circ} \mathrm{C} \pm 1{ }^{\circ} \mathrm{C}$ and relative humidity of $45 \%$ to $55 \%$ in a clean environment under 12:12 h light-dark cycle. The animals had free access to food pellets (Pranav Agro Industry, Bangalore, India) and purified water.

All the experimental protocols were approved by Institutional Animal Ethics Committee (IAEC) of the Himalaya Drug Company and were conducted according to the guidelines of Committee for the Purpose of Control and Supervision of Experimentation on Animals (CPCSEA), India.

\subsection{In Vivo Studies}

Forty eight wistar rats (24 males and 24 females) were divided in to 3 groups of 16 each (G-I to G-III), each group consists of 8 males and 8 female animals. The male and female animals were housed separately in a false bottom cages. All the animals were provided with standard laboratory diet (Nutrilab). G-I served as Normal control (DM water, $20 \mathrm{ml} / \mathrm{kg}$, p.o.), G-II received FFD410 (2.5 g/kg, p.o) and G-III received FFD-410 (5.0 g/kg, p.o.). The treatments were given for 90 days; feed intake and body weight were recorded every week till the end of the study. On $91^{\text {st }}$ day, blood samples were collected from all the animals for the estimation of hematological and biochemical parameters. At the end of $10^{\text {th }}$ week, the short-term cognition was evaluated for all the animals by modified elevated plus maze test.

\subsubsection{Effect of FFD-410 on Cognitive Functions in Rats by Modified Elevated plus Maze Test}

At the end of $10^{\text {th }}$ week, one hour after the last administration, all the animals were tested on elevated plus maze for transfer latency. In brief, each animal was placed individually at the end of open arm facing away from centre of the maze and the time taken by animal to enter from open to closed arm is recorded (Transfer Latency). On day-1, all the animals were allowed to explore the plus maze for $90 \mathrm{sec}$, if the animal did not enter into one of the enclosed arm within $90 \mathrm{sec}$, it is gently pushed to one of the enclosed arms and TL was recorded as $90 \mathrm{sec}$ $\left(1^{\text {st }}\right.$ trial) and animal were allowed to explore the maze for another $10 \mathrm{sec}$ and returned into the home cages after the $1^{\text {st }}$ trial. Retention latency (RT) was assessed 24 hrs later, $1 \mathrm{hr}$ after the drug administration.

\subsubsection{Effect of FFD-410 on Serum Immunoglobulins}

After scheduled treatment of FFD-410 for 10 weeks, blood samples were collected from all the animals and serum was separated used for estimation of immunoglobulin levels. A control tube containing $6 \mathrm{ml}$ of distilled water was used as sample blank for each serum sample to be analyzed. To $6 \mathrm{ml}$ of zinc sulphate solution $0.1 \mathrm{ml}$ of serum was added, the test tube was inverted to enable complete mixing of the reagents with the serum and al- 
lowed to stand for $1 \mathrm{~h}$ at room temperature. The first tube served as blank and the second tube was taken as sample. The turbidity developed was measured. The turbidity obtained (sample-blank) was compared with that obtained with standard barium sulphate $\left(\mathrm{BaSO}_{4}\right)$ solution. The turbidity obtained with this solution was expressed as zinc sulphate turbidity (ZST) units.Also, at the end of $10^{\text {th }}$ week, all the animals were sensitized with a single intraperitoneal injection of $0.1 \mathrm{ml}$ Sheep Red Blood Cells (SRBC $5 \times 10^{8}$ cells in PBS). On day 5 of sensitization, the blood samples were collected and subjected for estimation of hemagglutination antibody titre (HA Titre) with SRBC.

At the end of 90 days of treatment, blood samples were collected from all the animals for estimation of vital biochemical and haematological parameters, also the organs were collected, weighed and expressed as relative organ weight per body weight.

\subsection{In Vitro Antioxidant Activity}

Preparation of Test Drug Solution: All the drugs were prepared in DM water with a stock concentration of 10 $\mathrm{mg} / \mathrm{ml}$ only water-soluble portion were used for the assay.

\subsubsection{In Vitro DPPH Radical Scavenging Activity}

DPPH Radical Scavenging Activity: To the $100 \mu \mathrm{l}$ of test drug solution in water at different concentrations (The stock sample solutions was serially diluted with respective solvents to obtain lower dilutions) $100 \mu \mathrm{l}$ of $0.1 \mathrm{mM}$ solution of DPPH in ethanol was added. Thirty minutes later, the absorbance was measured at $517 \mathrm{~nm}$. Lower absorbance of the reaction mixture indicates higher free radical scavenging activity. Vitamin $\mathrm{C}$ was used as standard. The capability to scavengse the DPPH radical was calculated using the following equation:

$$
\begin{aligned}
& \text { DHHP Scavenged (\%) } \\
& =\frac{(\text { Absorbance of Control }- \text { Absorbance of Test })}{\text { Absorbance of Control }} \times 100
\end{aligned}
$$

The antioxidant activity of the test drug was expressed as $\mathrm{IC}_{50}(\mathrm{mcg} / \mathrm{ml})$. The $\mathrm{IC}_{50}(\mathrm{mcg} / \mathrm{ml})$ value is defined as the concentration (in $\mu \mathrm{g} / \mathrm{ml}$ ) of test drug that inhibits the formation of DPPH radicals by $50 \%$. The assays were run in quadruplicate and the average $\mathrm{IC}_{50}(\mathrm{mcg} / \mathrm{ml})$ value was calculated and compared against the standard [16].

\subsubsection{Reducing Power Assay}

This method employs the $\mathrm{Fe}^{3+}-\mathrm{Fe}^{2+}$ redox system and change absorbance with respect to concentration are recorded and plotted in the form of graph. Various concentrations of drug (The stock sample solutions were serially diluted to obtain lower dilutions) in $1.0 \mathrm{ml}$ of deionized water was mixed with phosphate buffer $(2.5 \mathrm{ml}, 0.2 \mathrm{M}$,
$\mathrm{pH}$ 6.6) and $1 \%$ potassium ferricyanide $(2.5 \mathrm{ml})$. The mixture was incubated at $50^{\circ} \mathrm{C}$ for 20 min's. Aliquots of trichloroacetic acid $(2.5 \mathrm{ml}, 10 \%)$ were added to the mixture, which was then centrifuged at $1036 \times \mathrm{g}$ for $10 \mathrm{~min}$. The upper layer of solution $(2.5 \mathrm{ml})$ was mixed with distilled water $(2.5 \mathrm{ml})$ and a freshly prepared $\mathrm{FeCl}_{3}$ solution $(0.5 \mathrm{ml}, 0.1 \%)$. The absorbance measured at $700 \mathrm{~nm}$. Increased absorbance of the reaction mixture indicates increased reducing power. Alternatively the assay was also miniaturized and was carried out in 96-well plate (Tarsons), where, volumes of reagents were proportionally reduced. The absorbance of each well was read using BIOTEK multimode (SYNERGY-HT) plate reader [16].

\subsubsection{Oxygen Radical Absorbance Capacity (ORAC) Assay}

The ORAC procedure used an automated plate reader (Synergy ${ }^{\mathrm{TM}} \mathrm{HT}$ Multi-Detection Micro plate Reader KC4, Bio Tek, USA) with 96-well plates [16,17]. Analyses were conducted in phosphate buffer $\mathrm{pH} 7.4$ at 37 1C. Peroxyl radical was generated using 2, 2'-azobis (2-amidino-propane) dihydrochloride which was prepared fresh for each run. Fluorescein was used as the substrate. Fluorescence conditions were as follows: excitation at 485 $\mathrm{nm}$ and emission at $520 \mathrm{~nm}$. The standard curve was linear between 0 and $50 \mathrm{mM}$ Trolox. Results are expressed as Total ORAC value as TE/g (Trolox Equivalent per gram) of fresh sample.

\subsection{Statistical Analysis}

The values were expressed as mean \pm SEM. The results were analyzed statistically using one way ANOVA followed by dunnet's test to find out the level of significance. The minimum level of significance is fixed at $p<0.05$. All the in vitro antioxidant assays were carried out in triplicates, while the in vivo study was conducted at once.

\section{Results and Discussion}

From past few decades the use of phytochemicals, nutraceuticals and other herbal products have increased dramatically due to their low level of side effects and better therapeutic efficacy in providing health benefits [5]. Expanding research and anecdotal reports on nutraceuticals and related herbal products have convinced the healthcare community and the general population [5]. Numbers of nutritional supplements in the form of oral formulations have been developed from herbs are proved to be beneficial in treating the nutritional deficiency states. FFD-410 is one of such formulation developed by The Himalaya Drug Company, Bangalore, India and indicated as a heath supplement in pediatrics.

In present study, HiOwna-Jr. (FFD-410) was evaluated for its beneficial effect on parameters such as body weight, 
feed intake, biochemical and hematological paprameters, also evaluated for its beneficial effect on immunity, learning and memory in rats at $2.5 \mathrm{~g} / \mathrm{kg}$ and $5.0 \mathrm{~g} / \mathrm{kg}$. p.o.

\subsection{Effect of FFD-410 on Biochemical and Hematological Parameters}

There was no statistically significant change clinical biochemistry (Tables 1 and 2), hematological parameters (Table 3) and relative organ weights (Table 4) were observed after 90 days of FFD-410 treatment at 2.5 and 5.0 $\mathrm{g} / \mathrm{kg}$ dose levels. However there was statistically significant increase in hemoglobin and total RBC counts were observed in high dose of FFD-410 treated female rats. Further, there was a statistically significant decrease in SGPT and ALP levels were also observed at high dose treated male rats.

\subsection{Effect of FFD-410 on Immune System}

For evaluating the immunomodulatory property of FFD410, haemoagglutination test was conducted in rats to evaluate the effect of test formulations on humoral response. The findings of the study revealed that, pretreatment with FFD-410 (2.5 \& $5.0 \mathrm{~g} / \mathrm{kg})$ could boost the immune system significantly and dose dependently by increasing the titer values and serum immunoglobulin levels compared to control group (Figures 1(a) and (b)). Based on these findings it can be concluded that, FFD410 has immunostimulant property in rats upon long term administration.

\subsection{Effect of FFD-410 on Short Term Cognition and Memory}

In present study, the short term cognition of memory was evaluated by means of modified elevated plus-maze test; the outcomes of the study showed that, pretreatment with FFD-410 at 2.5 and $5.0 \mathrm{~g} / \mathrm{kg}$ for 90 days could appreciably decreased the transfer latency (TL) in a dose dependent manner, indicating beneficial effect of FFD-410 in improving the short-term cognition and memory (Figure 1(c)).

\subsection{Antioxidant and Free Radical Scavenging Activity of FFD-410}

Free radicals are atoms or groups of atoms with an odd (unpaired) number of electrons and can be formed when oxygen interacts with certain molecules. Once formed, these highly reactive radicals can start a chain reaction, like dominoes [18]. Their chief danger comes from the damage they can do when they react with important cellular components such as DNA, or the cell membrane and cells may function poorly or die if this occurs. Antioxidants are molecules which can safely interact with

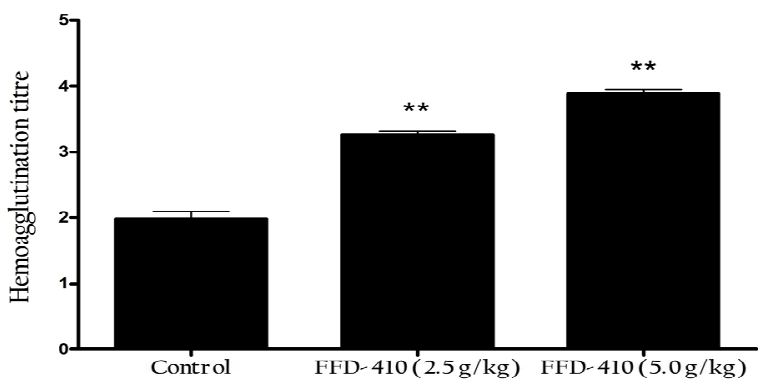

(a)

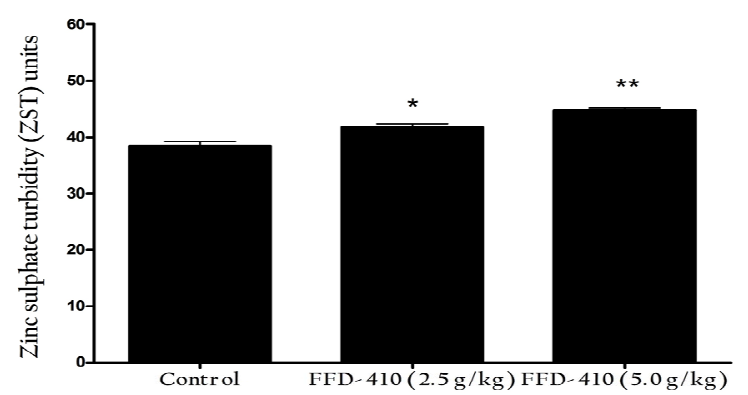

(b)

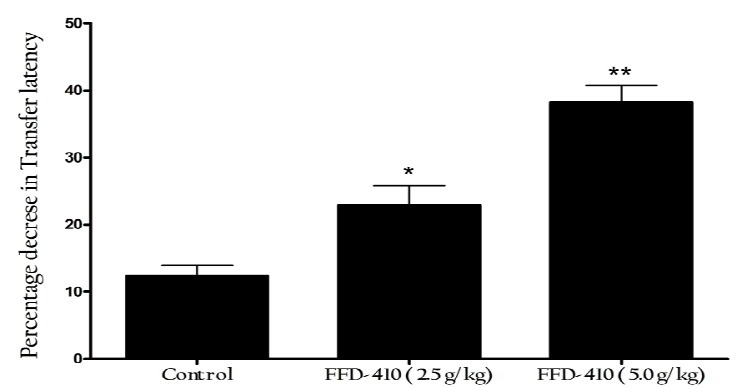

(c)

Figure 1. Effect of FFD-410 on (a) Sheep Red Blood Cellinduced hemoagglutination titre, (b) Serum immuno-globulin levels by ZnS turbidity assay and (c) Short-term cognition by elevated plus-maze test.

free radicals and terminate the chain reaction before vital molecules are damaged [19]. Although there are several enzyme systems within the body that scavenge free radicals, the body cannot manufacture these micronutrients, so they must be supplied in the diet $[18,19]$.

The food supplement rich in antioxidant constituents are thought to be much beneficial in treating oxidative stress-induced cell damage [20,21]. Especially the plant based constituents such as flavonoids and polyphenols are well proved to be highly beneficial in combating the oxidative stress-induced cellular damage by preventing the formation of free radicals and/or scavenging the formed oxidative radicals [18].

In present study, the in vitro antioxidant studies have showed that, FFD-410 a herbal based nutritionally balanced pediatric health drink has significantly and dose 
Table 1. Effect of FFD-410 on serum clinical chemistry parameters in male rats.

\begin{tabular}{cccc}
\hline Parameter & Control & FFD-410 (2.5 g/kg) & FFD-410 (5.0 g/kg) \\
\hline SGOT (IU/L) & $119.0 \pm 5.9$ & $117.1 \pm 3.8$ & $120.2 \pm 4.8$ \\
SGPT (IU/L) & $74.0 \pm 6.4$ & $67.3 \pm 4.2$ & $60.0 \pm 1.4^{*}$ \\
Phosphorous (mg/dl) & $5.3 \pm 0.1$ & $4.9 \pm 0.19$ & $5.1 \pm 0.19$ \\
Urea (mg/dl) & $39.3 \pm 1.6$ & $35.9 \pm 1.7$ & $37.5 \pm 3.0$ \\
Blood Urea Nitrogen (mg/dl) & $18.4 \pm 0.8$ & $16.8 \pm 0.80$ & $17.5 \pm 1.4$ \\
Alkaline Phosphatase (IU/L) & $175.6 \pm 11.5$ & $155.0 \pm 15.7$ & $135.7 \pm 6.3^{*}$ \\
Glucose (mg/dl) & $93.7 \pm 4.3$ & $84.6 \pm 4.4$ & $98.9 \pm 5.2$ \\
Cholesterol (mg/dl) & $63.3 \pm 3.0$ & $62.0 \pm 1.8$ & $67.0 \pm 4.3$ \\
Creatinine (mg/dl) & $0.69 \pm 0.01$ & $0.67 \pm 0.02$ & $0.70 \pm 0.02$ \\
Total protein (g/L) & $6.8 \pm 0.11$ & $7.1 \pm 0.09$ & $7.1 \pm 0.08$ \\
Triglycerides (mg/dl) & $107.9 \pm 9.1$ & $97.3 \pm 8.1$ & $114.2 \pm 8.3$ \\
VLDL-C (mg/d) & $21.6 \pm 1.8$ & $19.5 \pm 1.6$ & $22.8 \pm 1.6$ \\
Albumin (g/L) & $3.8 \pm 0.04$ & $3.8 \pm 0.06$ & $3.8 \pm 0.08$ \\
A:G Ratio & $1.3 \pm 0.04$ & $1.2 \pm 0.05$ & $1.8 \pm 0.06$ \\
Globulin (g/L) & $3.0 \pm 0.09$ & $3.3 \pm 0.10$ & $3.3 \pm 0.11$ \\
Calcium (mg/dl) & $8.8 \pm 0.11$ & $8.7 \pm 0.04$ & $9.1 \pm 0.08$ \\
HDL-C (mg/dl) & $53.7 \pm 1.9$ & $49.1 \pm 1.3$ & $55.2 \pm 2.1$ \\
Sodium (Na ${ }^{+}$) mmol & $152.5 \pm 2.4$ & $153.8 \pm 1.4$ & $157.5 \pm 1.9$ \\
Potassium (K') mmol & $5.3 \pm 0.15$ & $5.6 \pm 0.07$ & $5.5 \pm 0.10$
\end{tabular}

Note: SGPT, Serum glutamate pyruvate transaminase; SGOT, Serum glutamate oxaloacetate transaminase; HDL-C, High density lipoprotein cholesterol; LDL$\mathrm{C}$, Low density lipoprotein cholesterol; mmol, milli moles. All the values are expressed as mean $\pm \mathrm{SD}(\mathrm{n}=16)$; means of all the groups were statistically compared with control group by One way ANOVA followed by dunnet's test. " $\mathrm{p}<0.05$ compared to control group.

Table 2. Effect of FFD-410 on serum clinical chemistry parameters in female rats.

\begin{tabular}{cccc}
\hline Parameter & Control & FFD-410 (2.5 g/kg) & FFD-410 (5.0 g/kg) \\
\hline SGOT (IU/L) & $120.6 \pm 5.5$ & $117.6 \pm 3.4$ & $119.5 \pm 5.9$ \\
SGPT (IU/L) & $59.1 \pm 3.0$ & $54.6 \pm 2.9$ & $61.6 \pm 2.0$ \\
Phosphorous (mg/dl) & $4.4 \pm 0.11$ & $4.7 \pm 0.22$ & $4.9 \pm 0.18$ \\
Urea (mg/dl) & $40.2 \pm 1.1$ & $42.5 \pm 2.8$ & $41.5 \pm 1.3$ \\
Blood Urea Nitrogen (mg/dl) & $18.8 \pm 0.52$ & $19.9 \pm 1.3$ & $19.4 \pm 0.59$ \\
Alkaline Phosphatase (IU/L) & $107.1 \pm 9.7$ & $120.4 \pm 9.4$ & $121.6 \pm 19.1$ \\
Glucose (mg/dl) & $91.1 \pm 3.9$ & $89.8 \pm 2.6$ & $91.4 \pm 2.7$ \\
Cholesterol (mg/d) & $75.4 \pm 3.3$ & $74.0 \pm 2.7$ & $66.8 \pm 2.3$ \\
Creatinine (mg/dl) & $0.75 \pm 0.02$ & $0.73 \pm 0.01$ & $0.75 \pm 0.01$ \\
Total protein (g/L) & $7.6 \pm 0.15$ & $7.3 \pm 0.04$ & $7.5 \pm 0.06$ \\
Triglycerides (mg/dl) & $89.6 \pm 9.9$ & $92.3 \pm 7.3$ & $71.3 \pm 4.4$ \\
VLDL-C (mg/d) & $17.9 \pm 1.9$ & $18.4 \pm 1.5$ & $14.3 \pm 0.90$ \\
Albumin (g/L) & $4.1 \pm 0.08$ & $4.0 \pm 0.09$ & $3.9 \pm 0.06$ \\
A:G Ratio & $1.2 \pm 0.09$ & $1.2 \pm 0.07$ & $1.1 \pm 0.05$ \\
Globulin (g/L) & $3.5 \pm 0.21$ & $3.3 \pm 0.11$ & $3.6 \pm 0.11$ \\
Calcium (mg/dl) & $9.0 \pm 0.07$ & $8.8 \pm 0.06$ & $9.0 \pm 0.07$ \\
HDL-C (mg/dl) & $64.3 \pm 1.7$ & $64.9 \pm 2.2$ & $61.7 \pm 1.6$ \\
Sodium (Na $\mathbf{H}^{+}$) mmol & $150.4 \pm 0.41$ & $148.4 \pm 1.2$ & $147.9 \pm 0.97$ \\
Potassium (K') mmol & $4.8 \pm 0.18$ & $4.7 \pm 0.10$ & $4.7 \pm 0.10$
\end{tabular}

Note: SGPT, Serum glutamate pyruvate transaminase; SGOT, Serum glutamate oxaloacetate transaminase; HDL-C, High density lipoprotein cholesterol; LDLC, Low density lipoprotein cholesterol; mmol, milli moles. All the values are expressed as mean \pm SD $(n=16)$; means of all the groups were statistically compared with control group by One way ANOVA followed by dunnet’s test. 
Table 3. Effect of FFD-410 on hematological parameters.

\begin{tabular}{|c|c|c|c|c|}
\hline Sex & Parameter & Control & FFD-410 (2.5 g/kg) & FFD-410 (5.0 g/kg) \\
\hline \multirow{4}{*}{ Males } & WBC $\left(\mathrm{mm}^{3}\right)$ & $14.7 \pm 0.88$ & $16.2 \pm 0.87$ & $17.7 \pm 1.1$ \\
\hline & HGB (g\%) & $15.6 \pm 0.15$ & $15.6 \pm 0.25$ & $15.7 \pm 0.18$ \\
\hline & $\operatorname{RBC}\left(\mathbf{m m}^{3}\right)$ & $9.8 \pm 0.04$ & $9.8 \pm 0.15$ & $9.8 \pm 0.16$ \\
\hline & Clotting time (sec) & $174.0 \pm 12.0$ & $182.3 \pm 33.1$ & $177.5 \pm 15.6$ \\
\hline \multirow{4}{*}{ Females } & WBC $\left(\mathrm{mm}^{3}\right)$ & $14.3 \pm 2.1$ & $14.4 \pm 0.33$ & $14.6 \pm 1.2$ \\
\hline & HGB (g\%) & $14.8 \pm 0.11$ & $14.7 \pm 0.17$ & $15.5 \pm 0.17^{*}$ \\
\hline & $\operatorname{RBC}\left(\mathbf{m m}^{3}\right)$ & $8.6 \pm 0.11$ & $8.8 \pm 0.18$ & $9.2 \pm 0.13^{*}$ \\
\hline & Clotting time (sec) & $173.9 \pm 16.4$ & $187.4 \pm 12.5$ & $191.0 \pm 10.5$ \\
\hline
\end{tabular}

Note: WBC, White blood cell; HGB, Hemoglobin; RBC, Red blood cell. Values are expressed as mean \pm SD ( $n=16$ ); means of all the groups were statistically compared with control group by One way ANOVA followed by dunnet's test. ${ }^{*} \mathrm{p}<0.05$ compare to control group.

Table 4. Effect of FFD-410 on relative organ weight (gm/100 gm body weight).

\begin{tabular}{|c|c|c|c|c|}
\hline Sex & Organ & Control & FFD-410 (2.5 g/kg) & FFD-410 (5.0 g/kg) \\
\hline \multirow{9}{*}{ Males } & Adrenals & $0.015 \pm 0.01$ & $0.014 \pm 0.01$ & $0.013 \pm 0.01$ \\
\hline & Gonads & $0.001 \pm 0.001$ & $0.001 \pm 0.0004$ & $0.001 \pm 0.0006$ \\
\hline & Thymus & $0.091 \pm 0.002$ & $0.105 \pm 0.005$ & $0.097 \pm 0.008$ \\
\hline & Epididymes & $0.37 \pm 0.011$ & $0.39 \pm 0.010$ & $0.40 \pm 0.006$ \\
\hline & Spleen & $0.29 \pm 0.018$ & $0.29 \pm 0.018$ & $0.27 \pm 0.009$ \\
\hline & Heart & $0.36 \pm 0.010$ & $0.38 \pm 0.013$ & $0.35 \pm 0.008$ \\
\hline & Brain & $0.60 \pm 0.295$ & $0.64 \pm 0.011$ & $0.68 \pm 0.032$ \\
\hline & Kidney & $0.80 \pm 0.028$ & $0.80 \pm 0.016$ & $0.76 \pm 0.014$ \\
\hline & Liver & $3.1 \pm 0.08$ & $2.9 \pm 0.05$ & $2.9 \pm 0.07$ \\
\hline \multirow{8}{*}{ Females } & Adrenals & $0.028 \pm 0.004$ & $0.028 \pm 0.002$ & $0.030 \pm 0.002$ \\
\hline & Gonads & $0.036 \pm 0.017$ & $0.040 \pm 0.001$ & $0.041 \pm 0.002$ \\
\hline & Thymus & $0.151 \pm 0.006$ & $0.137 \pm 0.006$ & $0.132 \pm 0.004$ \\
\hline & Spleen & $0.338 \pm 0.020$ & $0.302 \pm 0.014$ & $0.396 \pm 0.034$ \\
\hline & Heart & $0.392 \pm 0.011$ & $0.408 \pm 0.017$ & $0.399 \pm 0.057$ \\
\hline & Brain & $0.85 \pm 0.022$ & $0.89 \pm 0.027$ & $0.84 \pm 0.021$ \\
\hline & Kidney & $0.76 \pm 0.021$ & $0.80 \pm 0.026$ & $0.76 \pm 0.022$ \\
\hline & Liver & $3.0 \pm 0.09$ & $2.9 \pm 0.09$ & $3.0 \pm 0.07$ \\
\hline
\end{tabular}

Values are expressed as mean \pm SD ( $=16)$; means of all the groups were statistically compared with control group by One way ANOVA followed by dunnet's test.

dependently scavenged the $\mathrm{DPPH}$ free radicals $\left(\mathrm{IC}_{50}\right.$ value $=1162.6)$ and absorbed the peroxyl free radicals in the ORAC assay (ORAC value = 76.1 TE/g). In addition, FFD-410 has showed dose denependent antioxidant activity in reducing power assay by increasing the absorbanve of the reaction mixture dose dependently (Table 5). These findings proved that FFD-410 can prevent the formation of free radicals and also scavenge the free radicals formed.

Eleusine coracana, Centella asiatica, Emblica officenalis and Piper nigrum are the chief constituents of FFD410, In literature various plant parts and isolated actives from these plant parts have been scientifically proved to possess various pharmacological properties such as antioxidant activity [22-24], immunomodulatory activity [2528], cytoprotective activity [29-32], cognitive and memory enhancing activity [33-36] and so on.

In present study, the combination of all these beneficial constituents in FFD-410 showed potent antioxidant and immunostimulant activities associated with enhanced cognitive functions through one/more mechanisms. Also, it is worth to note that high dose of FFD-410 tested has increased the total RBC count and hemoglobin content in female rats. 
Table 5. In vitro antioxidant activity of FFD-410.

\begin{tabular}{cccc}
\hline \multirow{3}{*}{ Sample } & \multicolumn{3}{c}{ Antioxidant Activity $^{*}$} \\
\cline { 2 - 4 } & $\begin{array}{c}\text { DPPH Assay } \\
\left(\mathbf{I C}_{50} \text { Value- }\right. \\
\mathbf{\mu g} / \mathbf{m l})\end{array}$ & $\begin{array}{c}\text { Reducing Power } \\
\text { Assay (\% increase } \\
\text { in Absorbance) }\end{array}$ & $\begin{array}{c}\text { ORAC } \\
\text { (TE/g) }\end{array}$ \\
\cline { 2 - 4 } FFD-410 & $1162.6 \pm 152.6$ & $255.0 \pm 31.2$ & $76.1 \pm 12.5$ \\
Vitamin C & $13.9 \pm 2.5$ & $7653.0 \pm 165.3$ & $3023.0 \pm 204.3$ \\
\hline
\end{tabular}

Note: DDPH, 1,1, Diphenyl-2-picrylhydrazyl; ORAC, Oxygen radical absorbance capacity. "Values given in the table are expressed as mean \pm SD for 3 trials $(n=3)$ carried out for each assay.

\section{Conclusion}

Our findings suggest that FFD-410 possess very good antioxidant, cognition and memory enhancing properties apart from being a good immuno stimulant. The FFD-410 (500 $\mathrm{mg} / \mathrm{kg}$ ) treated female animals, also showed mild but statistically significant increase in haemoglobin levels. However, 90 days of treatment with FFD-410 doesn't bring about any negative change in vital biochemical, haematological parameters and also relative organ weights, which could account for its wide safety of margin at tested dose levels (2.5 \& $5.0 \mathrm{~g} / \mathrm{kg}$, p.o.).

\section{Acknowledgements}

The authors are thankful to Dr. Shyam Ramakrishnan, Chief Scientific Officer, R\&D Center, The Himalaya Drug Company, Bangalore, India, for his constant support and encouragement.

\section{REFERENCES}

[1] R. Inaba, S. M. Mirbod and H. Sugiura, "Effects of Maharishi Amrit Kalash 5 as an Ayurvedic Herbal Food Supplement on Immune Functions in Aged Mice,” BMC Complementary and Alternative Medicine, Vol. 5, No. 8, 2005, pp. 1-10.

[2] H. Elizabete, D. B. Márcia and P. G. Denise, “Absorption and Bioavailability of the Minerals in the Multi-Mixture Food Supplement: Biological Assay in Rats," Aliment Nutrition, Vol. 19, No. 2, 2008, pp. 115-121.

[3] I. A. Siddiqui, F. Afaq, V. M. Adhami, N. Ahmad and H. Mukhtar, "Antioxidants of the Beverage Tea in Promotion of Human Health," Antioxidants and Redox Signaling, Vol. 6, No. 3, 2004, pp. 571-582. doi:10.1089/152308604773934323

[4] C. V. Lahaie, J. Bournival, M. Plouffe, J. Carange and M. G. Martinoli, "Sesamin Modulates Tyrosine Hydroxylase, Superoxide Dismutase, Catalase, Inducible NO Synthase and Interleukin-6 Expression in Dopaminergic Cells under MPP-Induced Oxidative Stress," Oxidantive Medicine and Cellular Longevity, Vol. 1, No. 1, 2008, pp. 54-62. doi:10.4161/oxim.1.1.6958
[5] B. Elida, Z. Daniel, P. Payal, J. Vishal, L. Tejas, K. Inna, S. J. Sidney and D. R. Sidhartha, "A Novel Dietary Supplement Containing Multiple Phytochemicals and Vitamins Elevates Hepatorenal and Cardiac Antioxidant Enzymes in the Absence of Significant Serum Chemistry and Genomic Changes," Oxidative Medicine and Cellular Longevity, Vol. 3, No. 2, 2010, pp. 129-144. doi:10.4161/oxim.3.2.11157

[6] T. Tanaka, H. Sugiura, R. Inaba, A. Nishikawa, A. Murakami, K. Koshimizu and H. Ohigashi, "Immunomodulatory Action of Citrus Auraptene on Macrophage Functions and Cytokine Production of Lymphocytes in Female BALB/c Mice,” Carcinogenesis, Vol. 20, No. 8, 1999, pp. 1471-1476. doi:10.1093/carcin/20.8.1471

[7] R. G. Ross, S. Selvasubramanian and S. Jayasundar, "Immunomodulatory Activity of Punica granatum in RabbitsA Preliminary Study," Journal of Ethnopharmacology, Vol. 78, No. 1, 2001, pp. 85-87. doi:10.1016/S0378-8741(01)00287-2

[8] D. L. Ricci, A. Giamperi and D. Bucchini, "Fraternale. Antioxidant Activity of Punica granatum Fruits," Fitoterapia, Vol. 77, No. 4, 2006, pp. 310-312. doi:10.1016/j.fitote.2006.01.008

[9] H. M. Sharma, A. N. Hanna, E. M. Kauffman and H. A. Newman, "Effect of Herbal Mixture Student Rasayana on Lipoxygenase Activity and Lipid Peroxidation," Free Radical Biology and Medicine, Vol. 18, No. 4, 1995, pp. 687-697. doi:10.1016/0891-5849(94)00197-R

[10] P. L. Ephraim and A. N. Robert, "Punica granatum (Pomegranate) and Its Potential for Prevention and Treatment of Inflammation and Cancer," Journal of Ethnopharmacology, Vol. 109, No. 2, 2007, pp. 177-206. doi:10.1016/j.jep.2006.09.006

[11] B. S. Ashok Kumar, K. Lakshman, K. N. Jayaveera, D. Sheshadri Shekar, K. Saleemulla, B. S. Thippeswamy and P. V. Veeresh, “Anti-Diabetic, Anti-Hyperlipidemic and Antioxidant Activities of Methanolic Extract of Amaranthus Viridis Linn in Alloxan Induced Diabetic Rats," Experimental and Toxicologic Pathology, Vol. 64, No. 1-2, 2012, pp. 75-79. doi:10.1016/j.etp.2010.06.009

[12] K. B. Ajay Kumar, M. Asheef, B. H. Babu and J. Padikkala, "The Inhibition of Gastric Mucosal Injury by Punica granatum L. (Pomegranate) Methanolic Extract,” Journal of Ethnopharmacology, Vol. 96, No. 1-2, 2005, pp. 171176. doi:10.1016/j.jep.2004.09.007

[13] K. D. Asish, C. M. Subhash, K. B. Sanjay, S. Sanghamitra, J. Das, B. P. Saha and M. Pal, "Studies on Antidiarrhoeal Activity of Punica granatum Seed Extract in Rats,” Journal of Ethnopharmacology, Vol. 68, No. 1-3, 1999, pp. 205-220. doi:10.1016/S0378-8741(99)00102-6

[14] A. Shalini, T. Prabhav, V. Ravichandra, D. Debashree and M. Forum, "Effect of Punica Granatum Peel Extract on Learning and Memory in Rats," Asian Pacific Journal of Tropical Medicine, Vol. 3, No. 9, 2010, pp. 687-690.

[15] E. A. Hayounia, K. Miled, S. Boubaker, Z. Bellasfar, M. Abedrabba, H. Iwaski, H. Oku. T. Matsui, F. Limam and M. Hamdi, "Hydroalcoholic Extract Based-Ointment from Punica Granatum L. Peels with Enhanced in Vivo Healing 
Potential on Dermal Wounds,” Phytomedicine, Vol. 18, No. 11, 2011, pp. 976-984. doi:10.1016/j.phymed.2011.02.011

[16] D. A. Suryakanth, M. Rafiq, M. Azeemuddin, G. L. Viswanatha, M. Jagadeesh, K. S. Sandeep Rao and P. S. Patki, "Free Radical Scavenging and Hepatoprotective Activity of HD-03/ES in Experimental Models," Journal of Experimental and Integrative Medicine, Vol. 2, No. 2, 2012, pp. 161-166.

[17] R. L. Prior, H. Hoang, L. Gu, X. Wu, M. Bacchiocca, L. Howard, W. M. Hampsch, D. Huang, B. Ou and R. Jacob, "Assays for Hydrophilic and Lipophilic Antioxidant Capacity (Oxygen Radical Absorbance Capacity (ORACFL)) of Plasma and Other Biological and Food Samples," Journal of Agriculture and Food Chemistry, Vol. 51, No. 11, 2003, pp. 3273-3279. doi:10.1021/jf0262256

[18] D. S. Abheri, R. M. Anisur and A. K. Ghosh, "Free Radicals and Their Role in Different Clinical Conditions: An Overview," International Journal of Pharmarmaceutical Science and Research, Vol. 1, No. 3, 2010, pp. 185-192.

[19] M. L. Urso and P. M. Clarkson, "Oxidative Stress, Exercise, and Antioxidant Supplementation,” Toxicology, Vol. 189, No. 2, 2003, pp. 41-54. doi:10.1016/S0300-483X(03)00151-3

[20] S. Umamaheswari, D. Prathiba, J. Srikanth and R. Umamaheswara, "Antioxidant Potential of a Polyherbal Formulation (Diabet) on Alloxan Induced Oxidative Stress in Rats,” Drug Invention Today, Vol. 1, No. 1, 2009, pp. 4649.

[21] A. Nauman, H. M. Malik, R. M. Safur, B. Samra, R. Sidra and H. G. Anwarul, "Antihypertensive, Antioxidant, Antidyslipidemic and Endothelial Modulating Activities of a Polyherbal Formulation (POL-10)," Vascular Pharmacology, Vol. 50, No. 2, 2009, pp. 57-64.

[22] G. Jayashree, K. G. Muraleedhara, S. Sudarslal and V. B. Jacob, “Anti-Oxidant Activity of Centella asiatica on Lymphoma-Bearing Mice,” Fitoterapia, Vol. 74, No. 5, 2003, pp. 431-434. doi:10.1016/S0367-326X(03)00121-7

[23] M. M. Shivananjappa and M. K. Joshi, "Influence of Emblica Officinalis Aqueous Extract on Growth and Antioxidant Defense System of Human Hepatoma Cell Line (HepG2),” Pharmceutical Biology, Vol. 50, No. 4, 2012, pp. 497-505. doi:10.3109/13880209.2011.618501

[24] G. A. Agbor, J. A. Vinson, J. Sortino and R. Johnson, “Antioxidant and Anti-Atherogenic Activities of Three Piper Species on Atherogenic Diet Fed Hamsters,” Experimental and Toxicologic Pathology, Vol. 64, No. 4, 2012, pp. 387-391. doi:10.1016/j.etp.2010.10.003

[25] M. G. Jayathirtha and S. H. Mishra, "Preliminary Immunomodulatory Activities of Methanol Extracts of Eclipta alba and Centella asiatica," Phytomedicine, Vol. 11, No. 4, 2004, pp. 361-365. doi:10.1078/0944711041495236

[26] R. Srikumar, N. Jeya Parthasarathy and R. Sheela Devi, "Immunomodulatory Activity of Triphala on Neutrophil Functions," Biological and Pharmaceutical Bulletin, Vol. 28, No. 8, 2005, pp. 1398-1403. doi:10.1248/bpb.28.1398
[27] A. F. Majdalawieh and R. I. Carr, "In Vitro Investigation of the Potential Immunomodulatory and Anti-Cancer Activities of Black Pepper (Piper Nigrum) and Cardamom (Elettaria Cardamomum)," Journal of Medicinal Food, Vol. 13, No. 2, 2010, pp. 371-381. doi:10.1089/jmf.2009.1131

[28] K. Punturee, C. P. Wild, W. Kasinrerk and U. Vinitketkumnuen, "Immunomodulatory Activities of Centella Asiatica and Rhinacanthus Nasutus Extracts," Asian Pacific Journal of Cancer Prevention, Vol. 6, No. 3, 2005, pp. 396-400.

[29] C. L. Cheng, J. S. Guo, J. Luk and M. W. Koo, “The Healing Effects of Centella Extract and Asiaticoside on Acetic Acid Induced Gastric Ulcers in Rats,” Life Sciences, Vol. 74, No. 18, 2004, pp. 2237-2249. doi:10.1016/j.lfs.2003.09.055

[30] A. Gnanapragasam, S. Yogeeta, R. Subhashini, K. K. Ebenezar, V. Sathish and T. Devaki, “Adriamycin Induced Myocardial Failure in Rats: Protective Role of Centella Asiatica," Molecular and Cellular Biochemistry, Vol. 294, No. 1-2, 2007, pp. 55-63. doi:10.1007/s11010-006-9245-0

[31] M. Sai Ram, D. Neetu, P. Deepti, M. Vandana, G. Ilavazhagan, D. Kumar and W. Selvamurthy, "Cytoprotective activity of Amla (Emblica officinalis) against Chromium (VI) Induced Oxidative Injury in Murine Macrophages," Phytotherapy Research, Vol. 17, No. 4, 2003, pp. 430433. doi:10.1002/ptr.1157

[32] N. Pathak and S. Khandelwal, "Cytoprotective and Immunomodulating Properties of Piperine on Murine Splenocytes: An in Vitro Study," European Journal of Pharmacology, Vol. 576, No. 1-3, 2007, pp. 160-170. doi:10.1016/j.ejphar.2007.07.033

[33] S. B. Rao, M. Chetana and P. Uma Devi, "Centella asiatica Treatment during Postnatal Period Enhances Learning and Memory in Mice,” Physiology and Behaviour, Vol. 86, No. 4, 2005, pp. 449-457. doi:10.1016/j.physbeh.2005.07.019

[34] P. Chonpathompikunlert, J. Wattanathorn and S. Muchimapura, "Piperine, the Main Alkaloid of Thai Black Pepper, Protects against Neurodegeneration and Cognitive Impairment in Animal Model of Cognitive Deficit like Condition of Alzheimer's Disease,” Food and Chemical Toxicology, Vol. 48, No. 3, 2010, pp. 798-802. doi:10.1016/j.fct.2009.12.009

[35] A. Soumyanath, Y. P. Zhong, E. Henson, T. Wadsworth, J. Bishop, B. G. Gold and J. F. Quinn, "Centella Asiatica Extract Improves Behavioral Deficits in a Mouse Model of Alzheimer's Disease: Investigation of a Possible Mechanism of Action," International Journal of Alzheimer's Disease, 2012, pp. 1-9. doi:10.1155/2012/381974

[36] M. Vasudevan and M. Parle, "Memory Enhancing Activity of Anwala Churna (Emblica Officinalis Gaertn): An Ayurvedic Preparation,” Physiology and Behaviour, Vol. 91, No. 1, 2007, pp. 46-54. doi:10.1016/j.physbeh.2007.01.016 